\title{
Vascular Effects of Auricular Acupuncture Evaluated via Two Digital Volume Pulse Measurements
}

\author{
José F. Rivas-Vilchis, Jorge Alberto Cervantes-Reyes \\ and Rubén Román-Ramos \\ Universidad Autónoma Metropolitana, campus Iztapalapa, \\ México
}

\section{Introduction}

Stimulation of some auricular acupoints produces changes in the radial pulse (Nogier, 1989), and electric stimulation of the auricular acupoint stomach can modify the radial artery pulse wave (Ikezono et al., 2003). Measurement of light transmission through the finger pulp during the cardiac cycle (photoplethysmography) provides a digital volume pulse (DVP). Changes in the contour of the DVP associated with aging, vascular disease, and drugs have been described (Dillon \& Hertzman, 1941; Morikawa, 1967). The contour of the DVP is mainly influenced by the systemic vasculature (Nichols, 2005).

A previous study has shown that the acute effects of manual acupuncture at the acupoint 6 of pericardium channel (PC6) on vascular pathophysiology in healthy and hypertensive subjects (Rivas-Vilchis et al, 2007), and non-smokers versus smokers (Rivas-Vilchis et al., 2008) can be detected by changes in the indices obtained from the second derivative of the DVP. Two indices derived from the DVP have been proposed. $\mathrm{R}_{\mathrm{DVP}}$ as an index of pressure wave reflection and $\mathrm{SI}_{\mathrm{DVP}}$ as an estimate of pulse wave velocity (PWV) in the aorta and large arteries, i.e., an index of large artery stiffness (Chowienczyk et al., 1999; Millasseau et al., 2002; Millasseau et al., 2003). The purpose of the present study was to assess the acute differential vascular effects of auricular acupoints located in the right and left ear using two DVP indices.

\section{Materials and methods}

\subsection{Subjects}

Forty healthy volunteers, $23.4 \pm 1.44$ years of age (mean $\pm S D$ ), were recruited by advertisement from our university. Studies were performed with the approval of the Research Ethics Committee of the División de Ciencias Biológicas y de la Salud, Universidad Autónoma Metropolitana at Iztapalapa, conducted in accordance with the Declaration of Helsinki (2008) of the World Medical Association, and with the informed and written consent of the subjects. Subjects were randomly assigned to group A $(n=20)$ or B $(n=20)$, corresponding to recordings obtained for the left or right ear, respectively. The experimental design is depicted in Table 1. Each treatment was followed by a 1-week washout period in order not to carry over vascular effect according previous experiments not depicted. 


\begin{tabular}{llll}
\hline Group A & $\begin{array}{l}\text { Left auricular acupoint } \\
\text { Shenmen }\end{array}$ & $\begin{array}{l}\text { Left auricular } \\
\text { acupoint Knee }\end{array}$ \\
\cline { 1 - 2 } Group B & $\begin{array}{l}\text { Right auricular acupoint } \\
\text { Shenmen }\end{array}$ & $\begin{array}{l}\text { Reek } \\
\text { washout period auricular } \\
\text { acupoint Knee }\end{array}$ \\
\hline
\end{tabular}

Table 1. Experimental groups and treatments.

\subsection{Methods}

Measurements were obtained while subjects were in the supine position after an overnight fast and at least $20 \mathrm{~min}$ rest in a quiet temperature-controlled clinical laboratory $\left(25 \pm 1^{\circ} \mathrm{C}\right)$ in order to achieve standard conditionsin all participants.

Acquisition of DVP. A photoplethysmograph (MP100, BIOPAC Systems, Goleta, CA, USA), which transmitted infrared light at $860 \pm 90 \mathrm{~nm}$, was placed on the index finger of either the right or left hand to obtain the DVP. The frequency response of the photoplethysmograph was flat at $10 \mathrm{~Hz}$. Digital output from the photoplethysmograph was recorded through a 12bit analog-to-digital converter with a sampling frequency of 200 points/s using the analysis platform provided by AcqKnowledge v. 3.9 software (BIOPAC Systems).

In each subject, a 7-min-long registration DVP was obtained. The acupuncture needle was inserted unilaterally and guided within a plastic tube into the designated auricular acupoint at a depth of $2 \mathrm{~mm}$. The needle was manually unilaterally stimulated for $5 \mathrm{~s}$ (60-65 s of registration period), contralateral to the side of the DVP recording, and was then immediately withdrawn.

The DVP indices obtained for each subject, corresponding to basal (25-35 s of the $1 \mathrm{~min}$ period before acupuncture) and post-acupuncture (365-385 s) periods, i.e, 5-min after acupuncture stimulation, were calculated using the average of 10 waves.

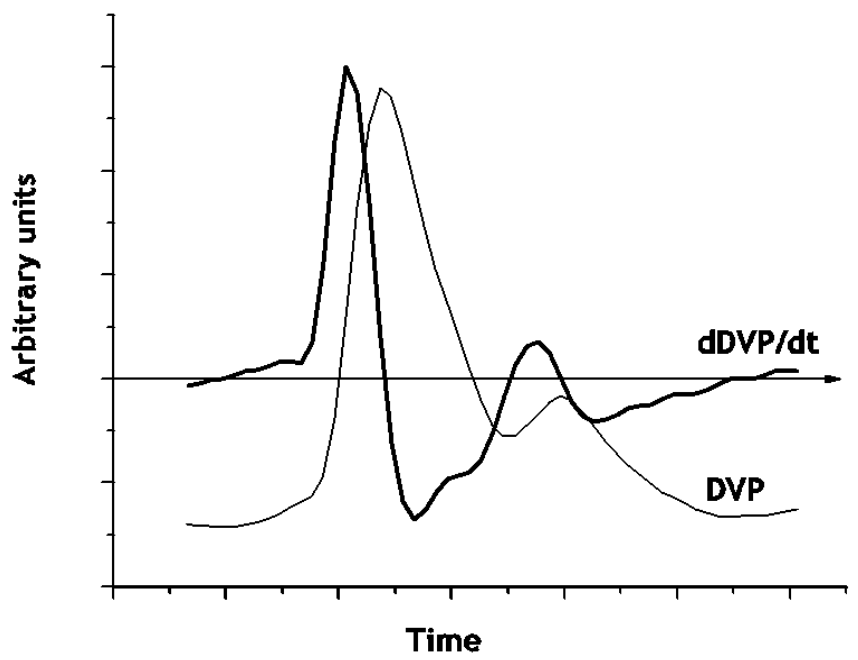

Fig. 1. DVP recording obtained by measuring the transmission of infrared light through the finger pulp, and its first derivative $(\mathrm{dDVP} / \mathrm{dt})$. 
The first derivative of the DVP wave contour was obtained using the Origin graphics analyzer v. 7.5 (Microcal Software, Inc., Northampton, MA, USA) to specify inflection points (Figure 1). $\mathrm{RI}_{\mathrm{DVP}}$ was determined as the height of the diastolic peak (or inflection point if no peak was present) and expressed as a percentage of the amplitude of the systolic peak. SIDVP was calculated based on the subject's height $(\mathrm{h})$ and the time between the systolic peak and diastolic peak/inflection points in the waveform $\left(\Delta \mathrm{T}_{\mathrm{DVP}}\right): \mathrm{SI}_{\mathrm{DVP}}=\mathrm{h} / \Delta \mathrm{T}_{\mathrm{DVP}}$.

$\mathrm{RI}_{\mathrm{DVP}}$ was thus determined based on the relative amplitudes of the systolic and diastolic components of the DVP and SI $\mathrm{DVP}_{\mathrm{P}}$ according to the relative timing of these components (Figure 2). The diastolic peak/inflection point was defined as the point at which the first derivative of the waveform was closest to zero (Millaseau et al., 2002). A distinct peak occurred when the first derivative was zero (positive-to-negative zero crossing). In the absence of a distinct peak, the point of inflection was defined as the point at which the first derivative was closest to zero.

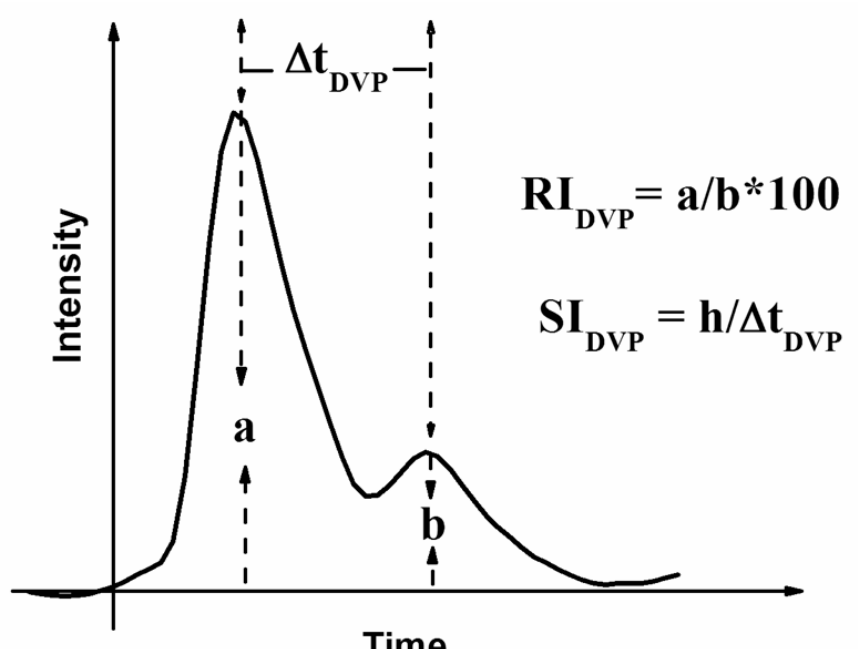

Fig. 2. $\mathrm{RI}_{\mathrm{DVP}}$ and $\mathrm{SI}_{\mathrm{DVP}}$ indices.

Acupuncture treatment. Acupuncture therapy was administered by a physician trained in both Western and traditional Chinese medicine. We used 1-cm long, 0.22-mm wide disposable stainless steel needles (Hwato, Suzhou, China), with no additional electrical or laser stimulation. The acupuncture needle was inserted unilaterally into the auricular acupoints Shenmen or Knee in the right or left auricle (Figure 3), gently stimulated for $5 \mathrm{~s}$, and then removed. With respect to the primary objective of the study, the clinical investigators responsible for calculating the DVP indices were blinded and did not know whether the data belonged to the Shenmen or Knee auricular acupoints in either the left or right ear. 


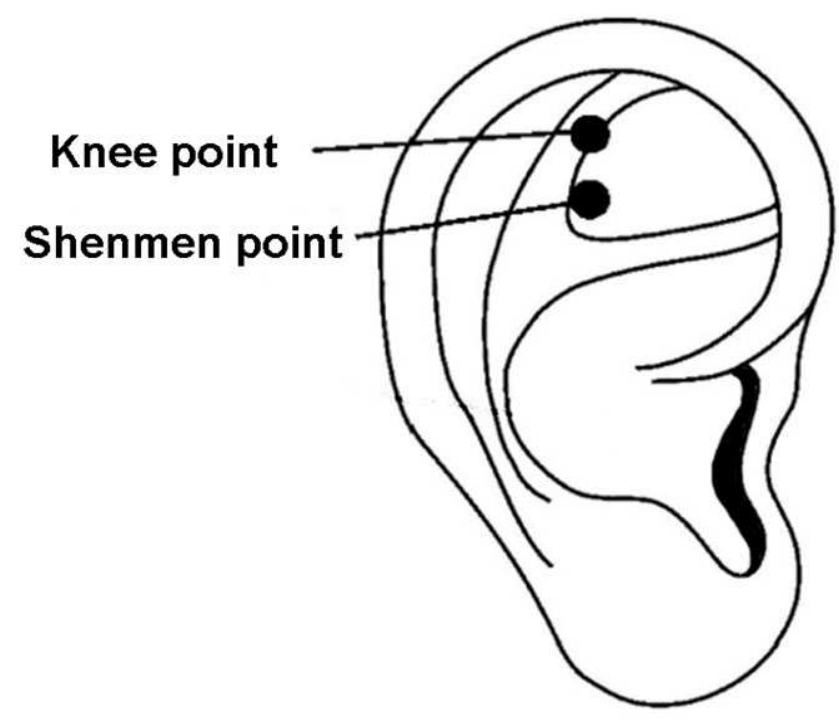

Fig. 3. Shenmen and Knee auricular acupoints.

Statistical analyses. Data are presented as means \pm SD (subject characteristics) or as means \pm SE (results). The Student's $t$ test was used to compare normally distributed continuous variables. $p<0.05$ was considered as significant, and all tests was two-sided. All statistical analyses were performed using SPSS software version 11.5 (SPSS Inc., Chicago, IL, USA).

\section{Results}

The study population consisted of 40 healthy male subjects having a global mean age of 23.4 \pm 1.44 (21-26) years. The experimental groups did not significantly differ with regard to age, body mass index, or other relevant cardiovascular characteristics. Figures 4 and 5 show the changes observed in the $\mathrm{RI}_{\mathrm{DVP}}$ and $\mathrm{SI}_{\mathrm{DVP}}$ indices between the pre- and post-acupuncture periods.

In healthy subjects, manual stimulation of the right Knee auricular acupoint significantly reduced the $\mathrm{RI}_{\mathrm{DVP}}$ (Figure 4) and manual stimulation of the left Knee auricular acupoint significantly increased the SIDVP index (Figure 5), when comparing the pre- vs. postacupuncture periods. Comparison of the post-acupuncture values revealed that the left Shenmen and Knee auricular acupoints elicited higher $\mathrm{RI}_{\mathrm{DVP}}$ index values than their counterpoints on the right $(p<0.05$ and $p<0.001$, respectively). 


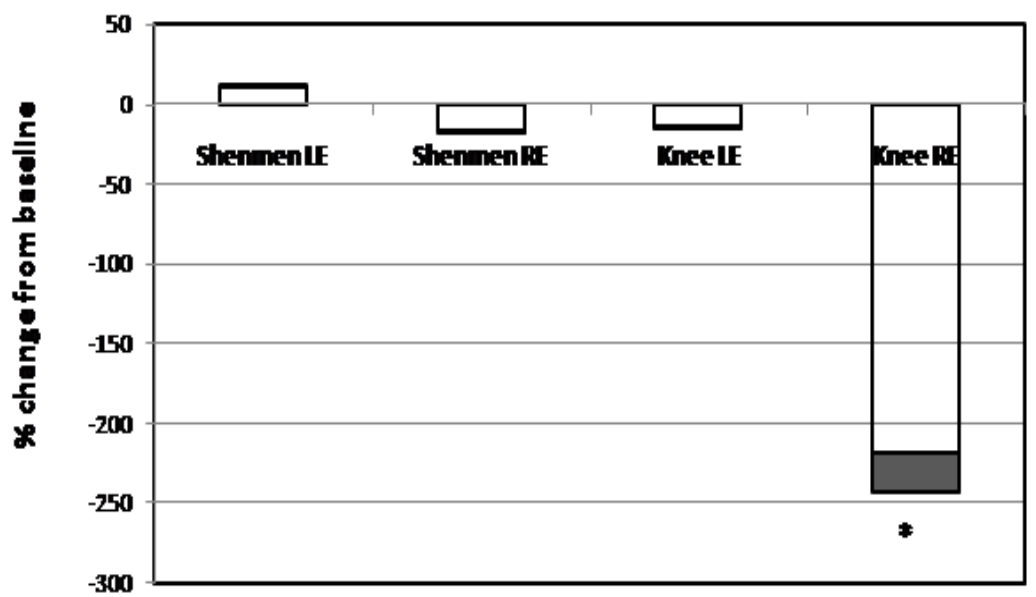

Fig. 4. Changes in percent units from baseline in $\mathrm{RI}_{\mathrm{DVP}}$ index in healthy men $(n=20)$ after 5 min of the five seconds acupuncture stimulation at the left or right auricular acupoints. $L E=$ left ear; RE = right ear. ${ }^{*} p<0.05$.

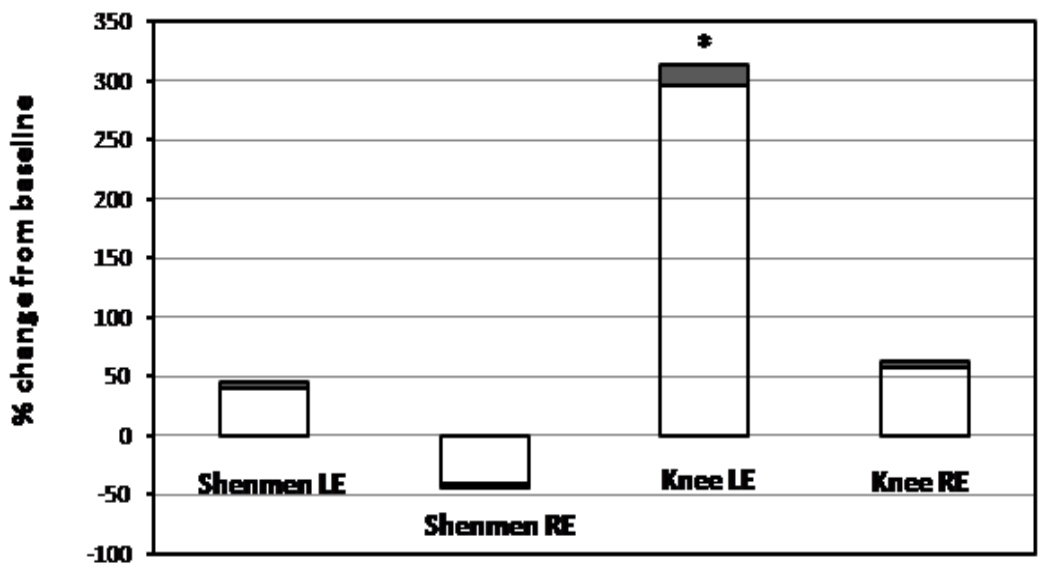

Fig. 5. Changes in percent units from baseline in SIDVP index in healthy men $(n=20)$ after 5 min of the five seconds acupuncture stimulation at the left or right auricular acupoints. $\mathrm{LE}=$ left ear; RE = right ear. ${ }^{*} p<0.05$. 


\section{Discussion}

The principal findings of the present study were that manual stimulation of the right and left Knee auricular acupoints in healthy subjects were associated with a significant decrease and increase in the RIDVP and SIDVP index, respectively. Auricular acupuncture elicited significant differences in $\mathrm{RI}_{\mathrm{DVP}}$ indices between the left and right ears for both the Shenmen and Knee acupoints, with lower values detected for the right auricular acupoints in both cases.

The principal findings of the present study were that manual stimulation of the right Knee acupoint was associated with significant decrease in the $\mathrm{RI}_{\mathrm{DVP}}$ and the left Knee acupoint was associated with significant increase in SIDVP index. Auricular acupuncture elicited significant differences in $\mathrm{RI}_{\mathrm{DVP}}$ indices between the left and right ears for both the Shenmen and Knee acupoints, with lower values detected for the right auricular acupoints in both cases.

Photoplethysmography provides a simple means of deriving the DVP. Several studies have revised the usefulness of the reflection and stiffness indices to assess and quantify effects of vasoactive drugs and nitrates in systemic haemodynamics, such as changes in heart rate and blood pressure (Wagner et al., 1990; Millaseau et al., 2006). To the best of our knowledge, $\mathrm{RI}_{\mathrm{DVP}}$ and $\mathrm{SI}_{\mathrm{DVP}}$ have not been previously used to study the vascular mechanisms of auricular acupoints. It has been suggested that DVP consists of a direct component arising from pressure waves propagating from the heart to the finger, as well as a delayed component arising from pressure waves reflected backward from the peripheral arteries, mainly in the lower body, which then propagate to the finger and possess a complex but predictable relationship with the aortic pulse pressure (Chowienczyk et al, 1999).

The $\mathrm{RI}_{\mathrm{DVP}}$ index provides a measure of the amount of wave reflection in systemic circulation (Millasseau et al, 2006). The $\mathrm{RI}_{\mathrm{DVP}}$ index is also sensitive to vasodilator inputs (Kelly et al., 2001; Stewart et al, 2003), it has been shown that nitrovasodilators such as glyceryl trinitrate produce reduction in RI index (Chowienczyk et al., 1999). SI DVP is derived from the subject's height and the timing of the diastolic peak/inflection point of the waveform (Figure 2). It provides an estimate of the pulse wave velocity (PWV) in the aorta and large arteries, and therefore the stiffness of the large artery (Chowienczyk et al., 1999; Millasseau et al., 2003). Therefore, it has been shown that the powerful vasoconstrictor angiotensin II increase SI $I_{D V P}$ index (Millasseau et al., 2003).

Auricular acupoints have been shown to produce therapeutic effects on cardiovascular pathophysiology (Huang \& Liang, 1992), as well as vascular peripheral modifications (Ikezono et al., 2003). The present findings demonstrating a correlation between needling the right Knee auricular acupoint and a decreased RIDVP index probably indicates that this procedure evoked a vagal response. On the other hand, the correlation between needling the left Knee auricular acupoint and an increased SIDVP index demonstrated herein indicates an increase in the PWV, most likely related to a sympathetic response. The RIDVP and SIDVP indices were selected because of their usefulness in assessing cardiovascular changes elicited by a variety of chemical and pharmacological stimuli. Our results clearly demonstrate the potential for auricular acupoints to modify these DVP indices.

\section{Conclusions}

The present study has one potential limitation, in that only two acupoints were analyzed. The mechanisms of the differences observed between right and left stimulation remain to be 
elucidated. Contour analysis of the DVP provides a rapid means of evaluating vascular tone and arterial stiffness, and therefore can be used to assess the cardiovascular effects and the related mechanisms associated with auricular acupoints.

\section{References}

[1] Nogier R. (1989) Auriculotherapy. Thieme Medical Pub.ISBN 3131480017, New York, USA

[2] Ikezono E, Ikezono T, Ackerman J] (2003) Establishing the existence of the active stomach point in the auricle utilizing radial artery tonometry] Am J Chin Med, Vol.31, pp] 285-294, ISSN 0192-415X

[3] Dillon JB, Hertzman AB] (1941) The form of the volume pulse in the finger pad in health, arteriosclerosis, and hypertension] Am Heart J, Vol.21, pp.172-190] ISSN 0002-8703

[4] Morikawa Y] (1967) Characteristic pulse wave caused by organic nitrates] Nature, Vol] 213, pp] 841-842] ISSN 0028-0836

[5] Nichols WW] (2005) Clinical measurement of arterial stiffness obtained from noninvasive pressure waveforms Am J Hypertens, Vol.18, pp] 3S-10S] ISSN 0895-7061

[6] Rivas-Vilchis JF, Hernández-Sánchez F, González-Camarena R, Suárez-Rodríguez LD, Escorcia-Gaona R, Cervantes-Reyes JA, Román-Ramos R] (2007) Assessment of the vascular effects of PC6 (Neiguan) using the second derivative of the finger photoplethysmogram in healthy and hypertensive subjects] Am J Chin Med, Vol] 35, pp] 427-436] ISSN 0192-415X

[7] Rivas-Vilchis JF, Escorcia-Gaona R, Cervantes-Reyes JA, Román-Ramos R] (2008) Vascular responses to manual PC6 acupuncture in nonsmokers and smokers assessed by the second derivative of the finger photoplethysmogram waveform] $J$ Acupuncture and Meridian Studies, Vol.1, No] 1, pp] 58-62] ISSN 2005-2901

[8] Chowienczyk PJ, Kelly RP, MacCallum H, Millasseau SC, Andersson TL, Gosling RG, Ritter JM, Anggård EE] (1999) Photoplethysmographic assessment of pulse wave reflection: blunted response to endothelium-dependent beta2-adrenergic vasodilation in type II diabetes mellitus] J Am Coll Cardiol, Vol.34, pp] 2007-2014] ISSN 0735-1097

[9] Millasseau SC, Kelly RP, Ritter JM, Chowienczyk PJ] (2002) Determination of age-related increases in large artery stiffness by digital pulse contour analysis] Clin Sci (Lond), Vol.103, pp] 371-377] ISSN 0143-5221

[10] Millasseau SC, Kelly RP, Ritter JM, Chowienczyk PJ] (2003) The vascular impact of aging and vasoactive drugs: comparison of two digital volume pulse measurements] Am J Hypertens, Vol.1, pp] 467-472] ISSN 0895-7061

[11] Wagner F, Siefert F, Trenk D, Jähnchen E] (1990) Relationship between pharmacokinetics and thermodynamic tolerance to isosorbide-5-mononitrate] Eur J Clin] Pharmacol, Vol.38, pp] S53-S59] ISSN 00316970

[12] Millasseau SC, Ritter J.M, Takazawa K, Chowienczyk PJ] (2006) Contour analysis of the photoplethysmographic pulse measured at the finger] J Hypertension, Vol.24, pp] 1449-1456] ISSN 0194911X 
[13] Kelly RP, Millasseau SC, Ritter JM, Chowienczyk PJ] (2001) Vasoactive drugs influence aortic augmentation index independently of pulse-wave velocity in healthy men] Hypertension, Vol.37, pp] 1429-1433] ISSN 0194911X

[14] Stewart AD, Millasseau SC, Kearney MT, Ritter JM, Chowienczyk PJ] (2003) Effect of inhibition of basal nitric oxide synthesis on carotid-femoral pulse wave velocity and augmentation index in humans] Hypertension, Vol.42, pp] 915-918] ISSN 0194911X

[15] Millasseau SC, Kelly RP, Ritter JM, Chowienczyk PJ] (2003) The vascular impact of aging and vasoactive drugs: comparison of two digital volume pulse measurements] Am J Hypertens, Vol.16, pp] 467-472] ISSN 0895-7061

[16] Huang H, Liang S] (1992) Acupuncture at otoacupoint heart for treatment of vascular hypertension] J Tradit Chin Med, Vol.12, No.2, pp] 133-136] ISSN 0254-6272 


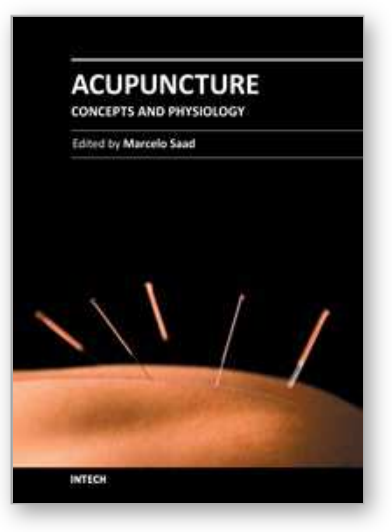

\author{
Acupuncture - Concepts and Physiology \\ Edited by Prof. Marcelo Saad
}

ISBN 978-953-307-410-8

Hard cover, 222 pages

Publisher InTech

Published online 10, October, 2011

Published in print edition October, 2011

Acupuncture and related techniques are useful tools for treating a spectrum of diseases. However, there are still many areas of controversy surrounding it. We hope this book can contribute to guide the advance of this ancient medical art. In the present work, the reader will find texts written by authors from different parts of the world. The chapters cover strategic areas to collaborate with the consolidation of the knowledge in acupuncture. The book doesnâ $€^{\mathrm{TM}} \mathrm{t}$ intend to solve all the questions regarding this issue but the main objective is to share elements to make acupuncture more and better understood at health systems worldwide.

\title{
How to reference
}

In order to correctly reference this scholarly work, feel free to copy and paste the following:

José F. Rivas-Vilchis, Jorge Alberto Cervantes-Reyes and Rubén Román-Ramos (2011). Vascular Effects of Auricular Acupuncture Evaluated via Two Digital Volume Pulse Measurements, Acupuncture - Concepts and Physiology, Prof. Marcelo Saad (Ed.), ISBN: 978-953-307-410-8, InTech, Available from:

http://www.intechopen.com/books/acupuncture-concepts-and-physiology/vascular-effects-of-auricularacupuncture-evaluated-via-two-digital-volume-pulse-measurements

\section{INTECH}

open science | open minds

\author{
InTech Europe \\ University Campus STeP Ri \\ Slavka Krautzeka 83/A \\ 51000 Rijeka, Croatia \\ Phone: +385 (51) 770447 \\ Fax: +385 (51) 686166 \\ www.intechopen.com
}

\author{
InTech China \\ Unit 405, Office Block, Hotel Equatorial Shanghai \\ No.65, Yan An Road (West), Shanghai, 200040, China \\ 中国上海市延安西路65号上海国际贵都大饭店办公楼 405 单元 \\ Phone: +86-21-62489820 \\ Fax: +86-21-62489821
}


(C) 2011 The Author(s). Licensee IntechOpen. This is an open access article distributed under the terms of the Creative Commons Attribution 3.0 License, which permits unrestricted use, distribution, and reproduction in any medium, provided the original work is properly cited. 